\title{
Participatory Ethnographic Film: Video Advocacy and Engagement with Q'eqchi' Maya Medical Practitioners in Belize
}

\author{
James B. Waldram
}

\begin{abstract}
There continues to be significant debate about what constitutes a "participatory ethnographic film." Contemporary standards for production require large budgets and sophisticated film crews, and as a result marginalizes those films produced at the local level designed to meet local needs. This article documents the process of creating a participatory ethnographic film at the behest of a group of Q'eqchi' Maya medical practitioners in Belize. From conception through to the approval of the final cut and distribution, the project was directed by the practitioners and executed on a shoestring budget and 'in kind' contributions. I argue that the genre of ethnographic film must accommodate local level aesthetic sensibilities about what constitutes a "good" representation of cultural issues, and consider the nature of the intended audience, thereby allowing space for a collaborative filmmaking process attendant to the world of the participants rather than that of international film festivals.
\end{abstract}

KEYWords participatory ethnographic film; Q'eqchi’ Maya; Belize; ethnography

Ethnographic film these days is dominated by professional filmmakers, whose credentials as ethnographers may be a little suspect in many cases. Of course, ethnographic film has traditionally been the purview of well-trained filmmakers, and one need only recall the works of such pioneers as Tim Asch here. But filmmaking in the early years required extensive technical equipment, resources, and skills not readily accessible to most ethnographers let alone their participants. And the goal was the production of cinematic or TV quality documentaries or, at the very least, films that would find their way into the core curriculum of introductory anthropology classes. Classic ethnographic film was modeled on modernist anthropology, an effort to portray visually what otherwise was written in ethnographies; it was a positivist approach to describing a "culture" (Marks, 1995; Ruby, 1975). There was nothing particularly participatory or engaged about it, and the research participant's role was largely to act out (or at least be filmed engaging in) the ceremony, ritual, hunt, or other aspects of daily life as they would if the cameras were not present. As Jay Ruby (1975) points out, the cultural portrayals generated in this manner were highly subjective and contributed to stereotyping and essentialism. They were examples of primitivist discourse, Edward Said's Orientalism, and "othering,' which in retrospect told us more about the anthropologist and anthropological/ western concerns than it did the people at the other end of the lens (Borjan, 2013). 
As anthropology entered its "crisis of representation" turn these issues rose to the fore, and culturally descriptive ethnographic films, sometimes including staged performances, gave way to a new approach which seemed more issue-oriented and more aesthetically vibrant, but less anthropological. I am not the first one to notice how anthropologists have been somewhat squeezed out of the ethnographic film enterprise, as indeed this process started some time ago. Back in 1998 Ruby offered a paper at the American Anthropological Association conference titled "The Death of Ethnographic Film" that argued that, "It is a genre constrained by marketplace... and dominated by filmmakers with no training or apparent interest in ethnography." There were exceptions to this, of course. The film series Millenium: Tribal Wisdom and the Modern World was created by Richard Meech, a Ph.D. in anthropology, and hosted by anthropologist David Maybury-Lewis, a founder of the engaged and activist organization Cultural Survival. Aired first in 1992, even this project was undertaken with an eye toward commercial success as well as a means of educating the public about the plight of many of the world's tribal peoples through poignant comparisons with westerners. Ethnographic film on that grand scale is invariably expensive, and the final product largely inaccessible to many of the people it portrays.

One response to issues of representation was the emergence of more participatory approaches, including the idea of providing the technology and training to people to allow them to tell their own stories (Gruber, 2016). The most famous of these is no doubt the project collaboration among anthropologists Sol Worth, John Adair, and members of the Navajo reservation, which culminated in a series of Navajo-controlled films and a monograph detailing the project (Worth \& Adair, 1997). More typical was the production of ethnographic films involving varying degrees of collaboration in which the filmmaker retained a strong measure of control over the process and the final product and followed certain cinematic conventions (Henley, 2020). Today, the situation is potentially much different. The digital age has brought us relatively user-friendly equipment and editing software; the shift from film to video has been revolutionary (Pink, 2013), and some compelling video can even be shot on a smartphone! Yet, despite the YouTube age we are in, ethnographic film has remained largely the domain of professional filmmakers and production companies. One need only explore the credentials behind most films shown at "ethnographic" film festivals to appreciate that "amateurs" are not all that welcome. As an example, a perusal of the feature films for the 2019 Ethnographic Film festival of the Royal Anthropological Institute, arguably the most important such festival in the world, is almost completely lacking in references to ethnography, and promotes the work of professional - and in some cases, Oscar-nominated - filmmakers. Digging into the program one does find some anthropological involvement, but this is overshadowed by the Hollywoodization of the genre in general as exhibited at this festival. The idea that what makes a film ethnographic is a solid grounding in ethnographic research as a first step seems to have been lost (Henley, 2020).

Ethnographic film today is big business, the search for adequate funding is time-consuming, and anthropologists are cautioned about entering into partnerships with commercial documentary film companies to underwrite their projects (Jell-Bahlsen, 2003). Big festivals, 
like that of the Royal Anthropological Institute, or the Margaret Mead Documentary Film Festival of the American Museum of Natural History, and companies such as Documentary Ethnographic Resources — or DER — are emerging as the arbiters of what constitutes a quality ethnographic film. Other firms, such as Elemental Productions (owned by an anthropologist), tell us what a good ethnographic film should look like, and not surprisingly a lot like the ones that they produce (eg. Lemelson \& Tucker, 2015). Most ethnographic films are made for a western audience to consume and are typically made on a for-profit basis. Western standards for performativity, cinematography, and narrative define the standards of success. Ethnographic accuracy is perhaps less important than producing a compelling story with some fabulous photography to back it up. But what if the standards for valuing the film are those of the subject participants themselves? More specifically, if we adopt a participatory action research approach, such as one defined by Jean Schensul and Margaret LeCompte (2016) and approach the participatory ethnographic film as an "emancipatory process that places actors affected by an issue at the heart of a research endeavor" (p. 332), then can we entertain alternative standards for judging the quality of research products, standards which are also defined by those very actors?

Accessible technology and software have led to an emergence of alt-ethnographic film based on a participatory model, and typically undertaken with limited funding and limited distribution. Professional anthropological filmmakers like Lemelson and Tucker (2015) can easily advocate for high levels of training and even collaborations with experts, arguing that,

It is not enough simply to have a camera available, since the kinds of footage appropriate for data collection and analysis, shot by an often unsteady hand, poorly lit, poorly composed, and with inadequate audio levels, will not necessarily be compelling, or even usable, when attempts are made to transform this material either into full-length films or even shorter compositions edited for lecture, conference, or translational presentations (p.31).

Compelling for what audience? Does their approach not structurally detach the very participants of our research from the ability to be more actively involved in telling their own stories? If we are to seriously embrace famed ethnographic filmmaker Jean Rouch's call for a "shared anthropology," or, in more contemporary terms, a "visually engaged ethnography" (Bell, 2016), then we must share the filmmaking process. The world's marginalized people the kind we often work with as anthropologists - do not have big film resources and, more importantly, may care little about producing a film about their plight that plays well in the art theatres of Santa Monica or the ethnographic film festival of the Royal Anthropological Association or the Margaret Mead Festival. What is "compelling" for them may involve values that are quite different from the aesthetic and cinematic values typically brought to bear in producing and assessing most contemporary ethnographic film undertaken for commercial purposes. What makes an ethnographic film "participatory," then, depends on the degree of meaningful participation, that is, moving beyond the subjects as actors to where the idea 
of the film, the topic, the contents, the imagery, and the intended audience are shaped if not defined by the participants themselves (Henley, 2020). Its foundation is in the robustness of relationships between the ethnographer and participants, and this cannot be established quickly.

I am not talking about ethnographic video recording solely for data collection; it is not Margaret Mead's camera-as-note-taker that she advocated many years ago (1963). Nor is this "ethnographic verité" filmmaking, where the subject is provoked "into revealing emotions and subtleties of unobservable culture" (Kahn, 2006, p.19). Such an approach, while valuable in some contexts, lends itself to the kinds of exotic voyeurism characteristic of ethnographic film festivals. Participatory ethnographic film is a means by which people - once our "participants" or "interlocutors" - can play an active role in the strategic production of a product that meets their goals and standards. It is filmmaking for their people that may have relevance beyond. It is collaborative by definition, with an appreciation that collaboration, contrary to what Ruby (1991) has suggested, does not require complete equality in all aspects of the filmmaking process; true collaboration is based on teamwork, with members of the team playing an equally important but often different role. In this article, I describe the unfolding process that leads to the production of one such film, and my role as a seasoned ethnographer but rookie filmmaker with no real budget, as I sought to honor the request of a group of Q'eqchi' medical practitioners for assistance.

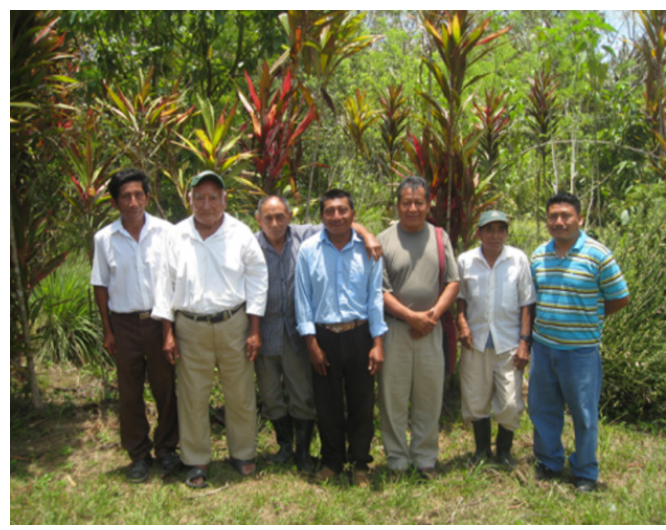

Figure 1. Members of the Maya Healers Association of Belize, (1-r): Francisco Caal, Manuel Baki, Lorenzo Choc, Emilio Kal, Victor Cal, Manuel Choc, Tomas Caal

\section{The Big Picture}

I have been working with a group of Q'eqchi Maya iloneleb', or medical practitioners, in the Toledo District of southern Belize for more than fifteen years. The Q'eqchi' are one of three "Maya" groups in Belize (along with the Mopan and Yucatec). The Maya as a whole represent only ten percent of the total national population of some 340,000 people. However, in the southern Toledo District they constitute almost two-thirds of the population, with the Q'eqchi' in particular the largest Maya group at roughly half the district population. They live in many small villages throughout the district, some quite remote but others along highways, and also in the southern regional capital of Punta Gorda.

While the Spanish initially controlled the territory that would become Belize, in 1862 Britain claimed the territory and created British Honduras. In 1981, the colony was granted independence and became Belize. While the British presence lead to the use of English as the official language, Spanish remains an important second language in many of the Q'eqchi' 
villages in Toledo. Indeed, many Q'eqchi' trace their families to neighboring Guatemala, where they continue to have many relatives. There was a significant exodus of Q'eqchi' from Guatemala to the Toledo district during the violence of the Guatemalan civil conflicts in the 1970s and 1980s. Several of the iloneleb' are from the Petén province of Guatemala.

The eight iloneleb' with whom I have worked came together in 1999 to form an association, known initially as the "Q'eqchi' Healers Association," and subsequently the "Maya Healers Association of Belize," as a response to a declining interest among their people in the knowledge and practice of Q'eqchi' medicine (Waldram, Cal, \& Maquin, 2009). I was initially contacted by them to research their medical practices, thanks to a former student who was doing some development work in Belize after Hurricane Iris in 2001. The practitioners had been involved in some research with botanists from Canada and Costa Rica, who were studying their plant medicines. However, they were concerned that such a narrow focus would lead to misunderstanding of the comprehensive and integrated nature of their medical practice, in which the use of botanicals, while important, was just one element.

The Q'eqchi' practitioner's continued interest in research is guided by several main concerns: their own people are being discouraged from pursuing traditional ways by church influence in the formal education system and aggressive tactics of US-based evangelical Christian churches; there are serious environmental threats to their way of life, including the medicinal plants that are central to their work; biomedical services in the southern part of Belize are still rudimentary, and they see an on-going need for their medical services; they have made few in-roads in attempting to work collaboratively with the government and its medical services branch; and they believe that their voices were not being heard as Belize worked to formulate a cultural policy for the nation.

The overall goal of the research is to understand the Q'eqchi' medical system and explain it to others. These others include not only government and medical people in Belize, but the broader scientific and medical worlds beyond Belize. But the iloneleb' also wish to speak to their people. They understand that the interest in their work by "scientists" helps to counteract the vigorous opposition of the churches; it is a means of validating their knowledge so their people will take notice. So, in a nutshell, they wish to talk to everyone who is not a Q'eqchi' medical practitioner and recognize that the means to do so lies, in part, with allies such as myself. They recognize that translation of their knowledge into terms, and languages, that others can understand is central to this task. They see biomedicine as their comparator, and a powerful one at that, and so they do not shy from comparisons but rather encourage them. Many medical anthropologists would reject an explicit use of western knowledge to frame the knowledge of Indigenous peoples, but this is precisely what these Q'eqchi' medical practitioners want. This is a pragmatic reading of the power-laden post-colonial context in which they live. The essence of participatory research, of course, is to honour-not criticize- the goals of research participants.

The entire research agenda is shaped by the iloneleb', and over the years we have met regularly to discuss ideas for new directions to take our work. We have endeavored collaboratively to understand each other and slowly tease out a working model of Q'eqchi' medicine that can be 
translated to the world (Waldram 2020). To achieve this we have employed several different ethnographic methods, including interviews, observation, field walks, photovoice, clinical case analysis, and cognitive techniques like free lists and pile sorts. Part of my job has been to determine the best methods to achieve their goals, explain them and adapt as necessary, and employ them. The trust that has developed among us over the years is significant in that the iloneleb' have essentially deputized me to determine how best to undertake the research, and they have proven quite willing to wade adventurously into many data-gathering exercises that are very alien to them.

"The ideal arrangement," writes ethnographic film expert Karl Heider (2006), "is for the ethnographer to do the fieldwork first, complete the analysis and writing, and then return to the scene with a film-maker to shoot a film that has been carefully thought out based on the written work" (p. 112). As Heider (2006) encourages, many scholarly articles, a book, and public-oriented materials have been produced so far from our research, providing both description and analysis of the extensive data set that has accrued. I never planned to get into filmmaking, however.

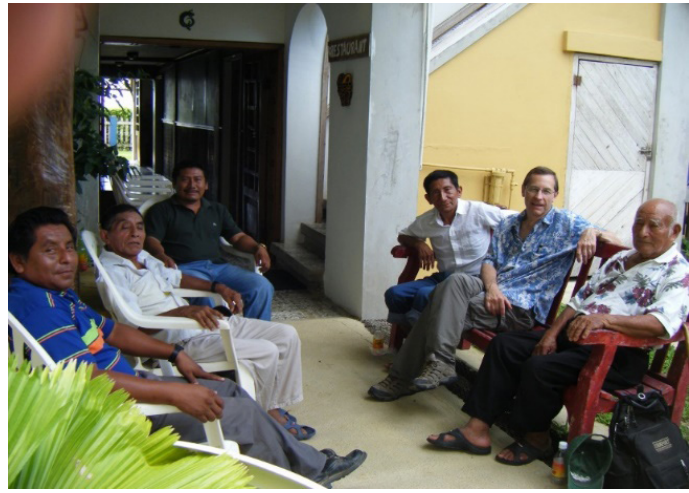

Figure 2. Film planning meeting, (1-r): Augustino Sho, Manuel Choc, Tomas Caal, Francisco Caal, James Waldram, Manuel Baki

\section{The Film-Making Process}

It was at one of our meetings that the practitioners mentioned that they would like me to make a film that would show the work they do and be distributed widely. Needless to say, I was very surprised by this request, as none of them have televisions and most lack electricity, and there is no cinema in their region. Yet they had enough experience and foresight to understand the potential power of this medium. Despite never having made a film, I agreed to help them. We talked at length about the point of the film, what it would - and could - show and what it would argue. We sought guidance through ceremony, in which those practitioners trained as Guia Espiritual Maya (Maya spiritual specialists) along with some others from nearby communities, prayed to Qaawa' ("God") for assistance in ensuring the well-being of all participants and the insight necessary to produce the stories of the iloneleb' respectfully and accurately. We had several meetings to refine ideas about content and work through potential problems in translating their medical work to film. For instance, when I suggested that the film would have to show some medical practices if it was to have any persuasive force at all - since viewers would most assuredly want to see this - there was considerable discussion about how this could be done since it seemed somewhat inappropriate to them to ask patients to allow filming. Their idea, with which they excitedly engaged, was to demonstrate procedures on each other's family members, simulations if you will, which, in the end, turned out to be real treatments! When we discussed the target audience for the film, they determined that, first and foremost, 
they wanted to talk to their people, and then the government and medical establishment. Therefore, the film should be in their language. But when they realized that few non-Q'eqchi' would be able to understand such a film, people such as government policy-makers and the medical establishment, I explained the idea of English sub-titles, which reassured them.

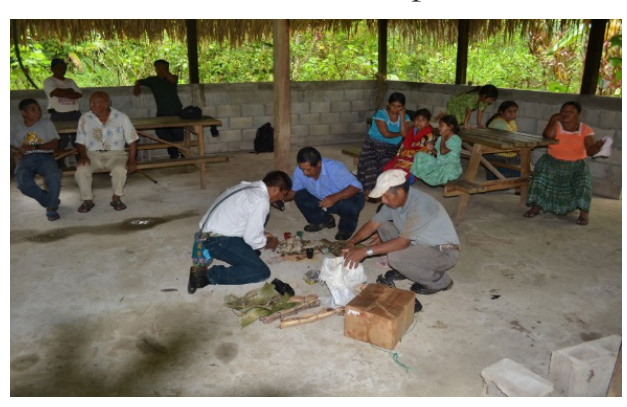

Figure 3. Preparing for ceremony to seek support for the film project

I returned to Canada to work on a script, pulling together the iloneleb' ideas and adding my own from the many hours of research interviews and participant-observation. I had many hours of video recorded already — the "research" video that those critics previously mentioned would suggest is inadequate for an ethnographic film-but the additional video was needed that was focused more directly on this project. Several trips back to Belize to workshop the script ensued before we were able to start shooting actual footage. And of course, once shooting began, the script needed to be rewritten several times. Throughout this process, I was aided by Q'eqchi' language and cultural expert, Tomas Caal. Tomas is one of the practitioner's sons and has deep knowledge about Q'eqchi' culture and medical practices, as well as important ethical sensibilities on the form and appropriateness of the representations we would document. While I did not replay footage to the practitioners during the production phase to get their feedback — what Jean Rouch has referred to as audio-visual reciprocityTomas was with me every step of the way as their representative. He was there during all the filming; he reviewed the clips and together we selected the ones to use. It is his voice that you hear narrating the film in Q'eqchi'. Frankly, this aspect of film production was one in which the iloneleb' had no interest in participating.

Several components were developed for the film. The iloneleb' sat for interviews about their work, often repeating information that they had previously provided in research-oriented interviews. They also demonstrated various treatment techniques, for both video and still shooting. Treatment sessions were recorded. And a variety of informative " $\mathrm{B}$ roll" video was taken to provide context, with the iloneleb' frequently suggesting what scenes should be filmed.

It was a most interesting process for us all once the filming began. Effectively, there were only three of us involved; I operated the camera, lights, and sound, and directed each scene, feeding the interview questions or acting directions to my Q'eqchi' colleague for translation. Tomas then worked to explain it all to the iloenelb', translate back to me, and

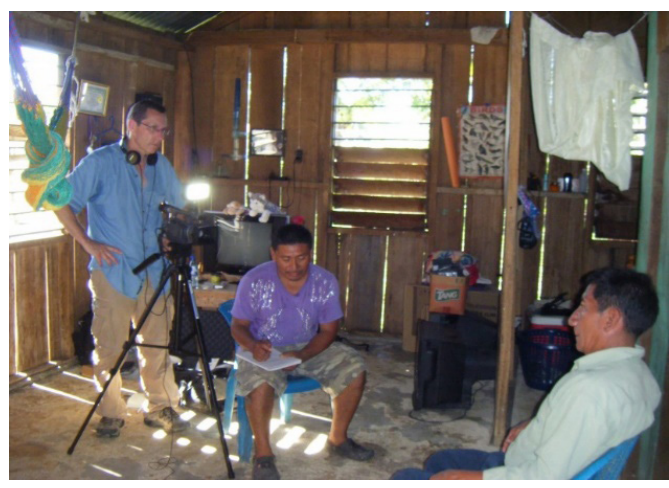

Figure 4. Filming an interview, (1-r): James Waldram, Tomas Caal, Francisco Caal 


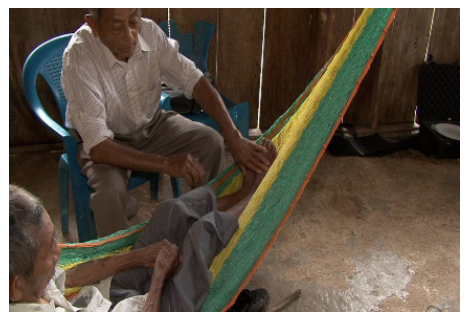

Figure 5. Ilonel Lorenzo Choc reading the pulse of a patient (still taken from the film)

offer invaluable advice as to what would or would not be appropriate to ask the iloneleb' to talk about or do. The third person was my graduate student, who admirably carried out the role of gofer and animal rustler (chickens, pigs, and dogs often wandered into the shoots). The iloneleb' were occasionally impatient while I fiddled with the camera, the lighting, or the microphone and audio levels, or requested that they reposition themselves or their patients to get a better angle or more suitable lighting (lighting in the houses was extremely variable). Sometimes they would start a treatment before I was ready, requiring me to interrupt them and ask them to restart. When I requested retakes and other changes they always complied.

We did try to have the iloneleb' dramatize certain aspects of the treatment process that we could not otherwise easily capture. For instance, we had one practitioner pretend to be a local villager to demonstrate the process of approaching an iloneb' to ask for help. They had trouble pretending and kept bursting into laughter in the middle of the scenes. When we finally had a complete scene recorded without interruption, I asked how "real" the encounter was. They started laughing again. We did not use these scenes.

As I noted, the treatment sessions that we recorded turned out to be real after all. We were not long into the process when I began to suspect that these were not "simulations." There is no difference between these and any other treatment sessions that I have witnessed. Each "patient" was a family member of another iloneleb' being treated for a real problem. As I learned, the idea of pretending to treat a patient was nonsensical; it could not be different from an actual treatment, and an actual treatment absolutely could not be undertaken with a non-suffering actor due to the inherent dangers to both practitioner and "patient." Further, pretending to treat represents a violation of the ethical code of conduct of the MHA and puts one at risk of being labeled a charlatan who convinces patients that they have a disorder to charge exorbitantly to treat it.

There were many complications, of course. Due to the high humidity, the camera lens would often steam up when I removed the cap, and take a half-hour or so to clear. The camera would sometimes over-heat, stopping filming while I took it apart and attempted to cool it down. The humidity and heat also seemed to combine at times to thwart my attempts to maintain camera focus. Chickens and other animals often appeared during the filming of treatment sessions, squawking into the microphone which was usually placed on the floor in a coffee cup (I did not have a boom). Some of the homes were so poorly lit that at times even with my portable lights the video remained dark and murky. Noise was ubiquitous. Many homes were built next to

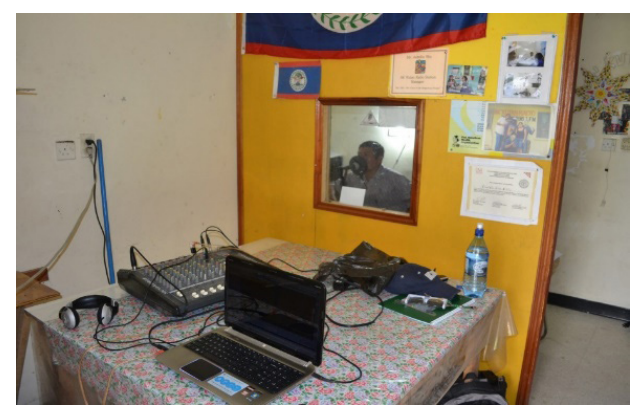

Figure 6. The recording studio 
highways and roads, yet even the most remote villages proved to be very noisy for filming. Gas-powered machines of all types, from weed whackers to old rumbling trucks, forced us to constantly stop and restart interviews. Family members were always present, going about their daily chores (the slapping sound of tortillas being made is surprisingly loud!). Children were very interested in the camera and what we were doing, and would often walk into the frame to stare at us, or climb on their father's knee during the shooting of an interview. This is the Q'eqchi' way of filmmaking-Q'eqchi' cinema verite if you will. You do not create an artificial context for purportedly showing reality, even if that will lead to a more cinematic final product.

The script was recorded by my Q'eqchi' colleague Tomas in an abandoned radio shack in a small village, the only place we could find with a semblance of sound control due to some simple acoustic renovations to the broadcast studio (the tropical forest being a remarkably noisy place!). A local contact found us some of the old station equipment, a microphone, and a simple mixing board, and a villager with some experience to operate it all. The script, written initially in English by me and then translated into Q'eqchi' by Tomas, was pinned, page by page, to the wall of the studio where Tomas could easily see it while speaking into the microphone. We did two or three takes of each passage, consisting often of only one or two sentences at a time. Despite the stifling hot temperatures inside the shack - which we had to keep closed up during recording - we managed to record both Q'eqchi' and English tracks (keeping open the possibility of an English language version of the film).

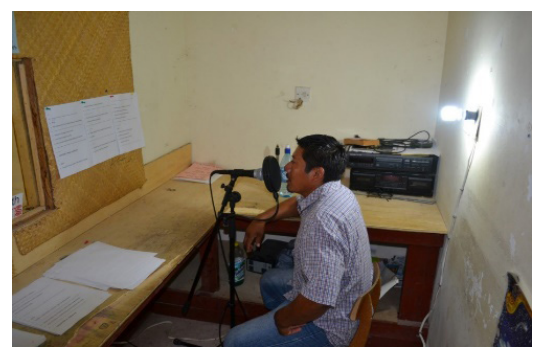

Figure 7. Tomas Caal recording the narration from script

Tomas and I took the recorded video footage and the audio and painstakingly matched the Q'eqchi' narration to the appropriate scenes, then confirmed the scene's English translation in preparation for the subtitles. I then returned to Canada, where I worked with the audiovisual unit at my university for post-production. I was well aware that film editing is a sophisticated technical process and that I would not develop sufficient expertise in a reasonable time to do this film justice. Using Final Cut Pro, the film editor and I put the video, stills, and audio narration together to produce a rough cut. The initial running time was about one hour and twenty minutes, far to long for our purposes. Ruthlessly cutting scenes we were able to reduce it to just under an hour.

I took the rough cut back to Belize to show the iloneleb', seeking their feedback and approval to move forward to the next step of producing a final cut. The only place we could find that was capable of showing the film was a rural bar with a karaoke set-up; we did our work in the morning before it opened at noon. I started the session by explaining what they would see and what issues I felt might still need to be addressed, and then I showed them the rough cut. As they watched with stony, expressionless faces, I became increasingly worried that they did not like it. I had tried to make an aesthetically pleasing film, but Q'eqchi' aesthetics are different, I learned. The film ended. No applause (I learned that clapping one's hands together is not 
a common way of showing favour). Just quiet.

We moved over to a table and opened a discussion about the film. No one commented on the aesthetics, the artful scene transitions, the soundtrack, the unfolding compelling narrative. They were concerned with the accuracy of the presentation, and whether or not the film would help them achieve their goals. Did I get it "right" from their perspective? They had several very concrete suggestions to amend the film, mostly some inclusions (such as showing more treatment paraphernalia because the

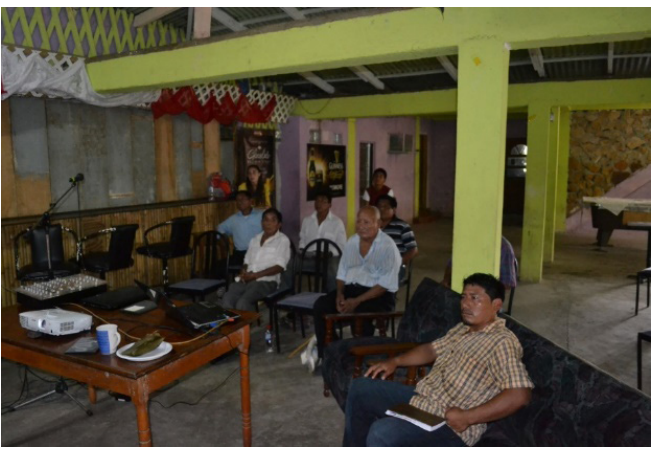

Figure 8. Members of the Maya Healers Association viewing the rough cut police kept rousting them on suspicion that their technological items and plant medicines were somehow illegal). After the meeting, when I asked a Q'eqchi' colleague if they liked the film, because I could not tell, he responded with an emphatic "Oh yes!"

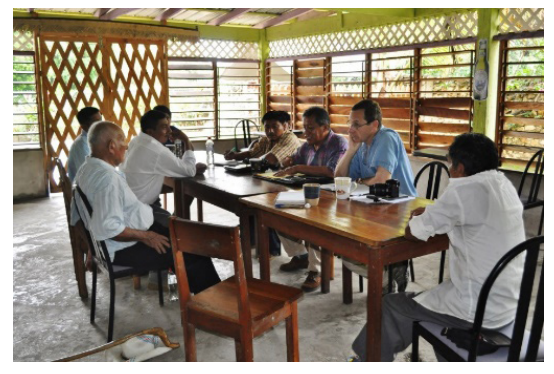

Figure 9. Post-viewing discussion of rough cut

I returned to Canada to undertake the final editing process, honouring the suggestions from the group, then found a Belize company to produce several hundred copies of the film for free distribution in the country. We titled the film Kawil Poyanam, Chaab'il Yu'am: Eb' Laj Ilonel Re B'elis," or "Healthy People, Beautiful Life: Maya Healers of Belize." I then traveled to southern Belize, where we celebrated the film's "world" premiere showing with the iloneleb' and their families in the same bar. Again, the audience showed little enthusiasm save for the end when one of the practitioners appeared playing his homemade fiddle while the credits rolled, and everyone laughed. The children seemed a little bored even though their fathers, mothers, and other family members were on TV. But in the end, there were smiles, followed by a feast and dancing. I was now certain that the film had met their expectations. I had got it "right."

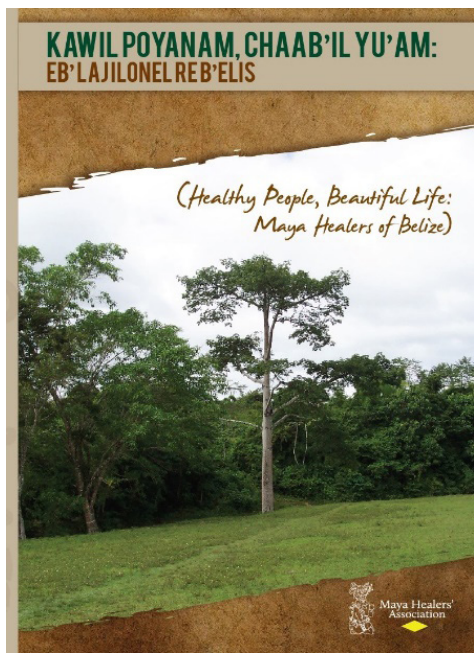

Figure 10. DVD cover, showing the sacred ceiba tree, symbol of the universe 


\section{Conclusion}

The definition of an "ethnographic" film, versus a documentary, remains somewhat contentious, but as Ruby (1975) argues, emulating an ethnography is key. This means there should be some kind of engagement with anthropological theory beyond the case portrayed. But this, of course, is representative of the modernist tradition of the time when he was writing, and did not anticipate what would become known as participatory ethnographic film. Indeed, it is hard to find a place between the ethnographic-documentary poles for participatory ethnographic film. This would be a place where the partnership between an anthropologist and a community does not aim to be explicitly anthropological nor contribute directly to theory, nor aim to be a commercial success, and yet strives more for accurate rather than exotic cultural representation following participant epistemological aesthetics.

A participatory ethnographic film can be defined by the active role of the participants in the portrayal of the "culture" on screen, with varying degrees of input and control from conceptualization to decisions where and to whom the film is intended to be shown. This can be an intense process. It would not be an understatement to say that none of us involved in the making of the film had any clue at the outset about how to do it. But at every step of the way we worked collaboratively to ensure that the film would meet the standards of the participants - the iloneleb' - even though at times what those standards were was not always evident because, frankly, they had never thought about how to portray their work cinematographically. What mattered to them was the accuracy of the message, and a Q'eqchi' message at that, one communicated in their language and their manner according to their cultural sensibilities understood and contextualized by their ultimate goal of educating others. The medium of film was simply the conduit to deliver that message. The form of the film was certainly a product of my doing, as they had no idea what such a film should look like, or how it should be put together to promote their message. In this sense, it can be criticized as representing a western cinematic form (although I had no training in that form) (Borjan, 2013; Henley, 2020). The film is linear, with clear episodes following (to me) a logical unfolding of the issues. But the content was theirs, a product of our many years of working together in the context of research as well as focused efforts to determine what should be in the film's message. This is a lesson of participatory filmmakers whose works are shaped significantly by non-Hollywood style aesthetic concerns (Flores, 2004). The film may not meet the production standards for the big international ethnographic film festivals, but it does meet the standards of the participants, and those standards come first in participatory work. The film remains freely available on Vimeo, Facebook, and YouTube, where it has been viewed over a thousand times so far and is now being used to educate government and medical staff. It is playing in schools, colleges, and village community centres throughout southern Belize. I realize that the right standards were honoured. I am happy that the film has also found its way into North American university courses. 
In 2013, ethnographic filmmaker and critic Jay Ruby wrote that,

New anthrofilmmakers seem uninterested in considering the question of how films communicate so that they might select the best cinematic style to convey their insights. They are afraid to take the chance of doing something stylistically different .... The digital revolution has not thus far produced an anthrofilm avant garde but rather an anthrofilm that is more and more retardataire [para $10]$.

Perhaps it will be the participatory ethnographic film that will represent this avant-garde, one that shifts the aesthetic standards to those of the people with whom we work and who have much at stake in the film's production, rather than those of the people who only consume. To once again return to Jean Rouch, I conclude with his observation that "This type of totally participatory research, as idealistic as it may seem, appears to me to be the only morally and scientifically feasible anthropological attitude today" (Rouch, 1973, pp. 11-12). Somewhat ironically, Rouch failed to live up to this mantra in his work (Gruber, 2016). However, we are in a new era, brought on by video technology, globalization, and decolonization, in which ethnographic film has become an important means by which peoples around the world can control the public image of their culture and the message they wish to communicate, a new wave concerned more with how film plays out among their peoples or in the hallways of power where decisions affecting them are made. It is a response to the elitism of contemporary ethnographic film, with its western aesthetics and Hollywood production values and budgets. It is a field rich for engaged research and collaboration.

\section{Acknowledgements}

The research upon which this article is based has been funded by the Social Sciences and Humanities Research Council of Canada (SSHRC). Ethics approval was granted by the Maya Healers Association of Belize, the National Institute of Culture and History (Belize), and the University of Saskatchewan. I appreciate the insightful comments of two anonymous reviewers of this article, and editors of these special issues, Sylvia Abonyi and Pamela Downe. I remain grateful for the friendship of the members of the Maya Healers Association, some of whom have passed on since this research was first started: Manuel Baki (late), Tomas Caal, Francisco Caal, Victor Cal, Lorenzo Choc (late), Manuel Choc, Emilio Kal, Albino Makin (late), and Augustino Sho. 


\section{About the Author}

James B. Waldram has a Ph.D. in applied medical anthropology and is a full professor in the Department of Archaeology and Anthropology at the University of Saskatchewan, Canada.. He is a Fellow of the Royal Society of Canada, and the 2016 winner of the Social Science and Humanities Research Council's Insight award for the research that is the subject of this article. Email: j.waldram@usask.ca

\section{References}

Bell, T. R. (2016). Visually engaged ethnography: Constructing knowledge and critical consciousness. Journal of Media Practice, 17, 126-137.

Borjab, E. (2013). Rethinking the Traditional in ethnographic film: Representation, ethics and indigeneity. Etnološka Tribuna, 36(43), 25-48.

Flores, C. Y. (2004). Indigenous video, development, and shared anthropology: A collaborative experience with Maya Q'eqchi' filmmakers in postwar Guatemala. Visual Anthropology Review, 20(1), 31-44.

Gruber, M. (2016). Participatory ethnographic filmmaking: Transcultural collaboration in research and filmmaking. Visual Ethnography, 5(1), 15-44.

Heider, K. G. (2006). Ethnographic Film. Revised Edition. Austin: University of Texas.

Henley, Paul. (2020). Beyond observation: A history of authorship in ethnographic film. Manchester: Manchester University.

Jell-Bahlsen, S. (2003). Funding ethnographic film and video productions in America. In P.

Hockings, ed. Principles of Visual Anthropology, $3^{\text {rd }}$ ed. Pp. 413-439. Berlin: Mouton de Gruyter.

Lemelson, R., \& Tucker, A. (2015). Steps toward an integration of psychological and visual anthropology: Issues raised in the production of the film series Afflictions: Culture and Mental Illness in Indonesia. Ethos, 43(1), 6-39.

Marks, D. (1995). Ethnography and ethnographic film: From Flaherty to Asch and After. American Anthropologist, 97(2), 339-347.

Mead, M. (1963). Anthropology and the camera. In W. D. Morgan, (Ed.), The Encyclopedia of Photography, Vol. 7, 166-184. New York: Greystone.

Pink, S. (2013). Doing Visual Ethnography, $3^{\text {rd }}$ ed. London: Sage.

Rouch, J. (1973). The Camera and Man. http://www.der.org/jean-rouch/pdf/CameraandMan-JRouch.pdf

Ruby, J. (1975). Is an ethnographic film a filmic ethnography? Studies in the Anthropology of Visual Communication, 2(2), 104-111.

Ruby, J. (1991) Speaking for, speaking about, speaking with, or speaking alongside: An Anthropological and Documentary Dilemma. Visual Anthropology Review, 7(2), 50-66.

Ruby, J. (1998). The death of ethnographic film. Paper presented at American Anthropological Association meeting, Philadelphia. http://astro.ocis 
Ruby, J. (2013). The digital revolution and anthropological Film.

Retrieved from http://savageminds.org/2013/11/03/the-digital-revolution-andanthropological-film, May 7, 2019.

Schensul, J. J., \& LeCompte, M.D. (2016). Ethnography in Action: A Mixed Methods Approach. Lanham, Maryland: Altamira.

Waldram, J. B., Cal, V., \& Maquin, P. (2009). The Q'eqchi Healers Association of Belize: An endogenous movement in Heritage preservation and management. Heritage Management, 2(1), 35-54.

Waldram, James B. (2020). An Imperative to Cure: Principles and Practice of Q'eqchi' Maya Medicine in Belize. Albuquerque: University of New Mexico.

Worth, S., \& Adair, J. (1997). Through Navajo Eyes: An Exploration in Film Communication in Anthropology. Albuquerque: University of New Mexico. 